\title{
Trends in Monthly Tropopause Characteristics Observed over Taipei, Taiwan*
}

\author{
M. ROJA RAMAN AND WEI-NAI CHEN \\ Research Center for Environmental Changes, Academia Sinica, Taipei, Taiwan
}

(Manuscript received 31 July 2013, in final form 2 November 2013)

\begin{abstract}
This study presents monthly trends in the cold-point tropopause (CPT), calculated using three decades of radiosonde data from 1981 to 2010 over Taipei, Taiwan $\left(25^{\circ} 01^{\prime} \mathrm{N}, 121^{\circ} 27^{\prime} \mathrm{E}\right)$. Multivariate regression analysis has been used to suppress the effect of natural variations, such as quasi-biennial oscillation (QBO), ENSO, solar cycle, and volcanic eruptions. From the continuous time series, statistically insignificant heating and a decrease in the height of CPT are observed. However, the trends estimated using individual monthly time series revealed new features with statistically significant increasing trends in CPT temperature at a rate of approximately $0.03^{\circ} \mathrm{C} \mathrm{yr}^{-1}$ and statistically significant decreasing trends in CPT height at a rate of approximately $4.7 \mathrm{~m} \mathrm{yr}^{-1}$ during summer months. An enhanced heating rate in the upper troposphere along with a suppressed cooling rate in the lower stratosphere observed over Taipei might have caused the tropopause heating trend during summer. The possible relationship between tropopause trends and lower-stratospheric ozone is also examined. The seasonal and spatial variations in trends estimated using NCEP-Climate Forecast System Reanalysis (CFSR) data reveal the spatial heterogeneity in CPT temperature trends. Initial inspection of monthly trends in tropopause characteristics suggests that the estimation of tropopause trends using the continuous time series may not exactly represent the long-term variability of individual months or seasons.
\end{abstract}

\section{Introduction}

The tropopause is the boundary between the convectively mixed troposphere and the relatively stable stratosphere that acts as a "two-way gate" for the exchange of mass, water vapor, and chemical species between the troposphere and the stratosphere (Fueglistaler et al. 2009; Nishimoto and Shiotani 2012). Although the tropopause is identified based on the dynamical, thermal, and chemical transitions in the upper troposphere-lower stratospheric (UTLS) region, the cold-point tropopause (CPT), which is defined as the height at which the coldest tropospheric temperature is noted, is preferred in studies of tropopause characteristics and cross-tropopause flux in the tropical region (Selkirk 1993). Since the vertical transport of water vapor and chemical compounds from the

\footnotetext{
* Supplemental information related to this paper is available at the Journals Online website: http://dx.doi.org/10.1175/JAS-D-130230.s1.

Corresponding author address: Wei-Nai Chen, Research Center for Environmental Changes, Academia Sinica, 128 Academia Road, Nangang, Taipei 115, Taiwan.

E-mail: wnchen@rcec.sinica.edu.tw
}

troposphere-stratosphere exchange through the tropopause affects the radiative flux balance in the UTLS region, long-term variability in the tropopause has been considered as a sensitive indicator of climate change (Holton et al. 1995; Sausen and Santer 2003; Santer et al. 2003; Son et al. 2009). In general, characteristics like the height and temperature of the tropopause vary over wide time scales, ranging from a few hours to decades in the regional as well as synoptic scales.

Several investigators have used the reanalysis and model-simulated datasets to study the long-term variation of tropopause characteristics and have come to different conclusions from each dataset. Santer et al. (2003) reported that the global tropopause pressure shows a decreasing trend of $1.13 \mathrm{hPa}$ decade ${ }^{-1}$ over 1979-93 in the European Centre for Medium-Range Weather Forecasts (ECMWF) reanalysis dataset and an even larger decreasing trend of $2.16 \mathrm{hPa}$ decade $^{-1}$ over $1979-2000$ in the National Centers for Environmental Prediction (NCEP) reanalysis data. These reported tropopause trends are usually biased owing to the low vertical resolution of the reanalysis datasets. Using chemistry-climate models (CCMs), Austin and Reichler (2008) conducted an experiment to simulate 140 years of climate in order to study the tropopause in the past, present, and future; their 
estimates show the tropopause height increasing steadily at a mean rate of $63 \pm 3 \mathrm{~m} \mathrm{decade}^{-1}$ but with a temperature trend of $-0.13^{\circ} \pm 0.07^{\circ} \mathrm{Cdecade}^{-1}$ before and $+0.254^{\circ} \pm 0.14^{\circ} \mathrm{C} \mathrm{decade}^{-1}$ after the year 2000 . Son et al. (2009) also did similar climate simulations and found that the tropopause height continues to increase in the future, but with a weak trend. Similarly, with a multimodel assessment of the UTLS region using 18 CCMs, Gettelman et al. (2010) reported a continuous decrease in tropopause pressure in the twenty-first century, along with an increase of approximately $1^{\circ} \mathrm{C}$ century ${ }^{-1}$ in cold-point tropopause temperature. Even after several studies, longterm variations of tropopause temperatures are poorly understood because of data uncertainties (Randel and Jensen 2013). Although the reanalysis and model datasets are good enough to study global variations in the tropopause, their main drawback has been their low vertical resolution.

Determining tropopause characteristics using radiosonde data benefits from their high vertical resolution and relatively less uncertainty, but monitoring on a global scale is limited because of the data largely being restricted to land areas and also because of the use of different types of sondes globally (Lewis 2009; Randel and Jensen 2013). However, on the regional scale, radiosonde data is the best suitable type for tropopause studies. Using the constant level balloon flight data from about 12 years, Angell and Korshover (1974) observed that there was an increase in the tropopause pressure with values varying from 5 to $7 \mathrm{hPa} \mathrm{decade}^{-1}$ and an increase in tropopause temperature in the tropics; they attributed these changes to the increase in the water vapor mixing ratio in the lower stratosphere. Following their study, Hofmann et al. (1974) found that there was an increase in the total ozone over the altitude interval from 500 to $200 \mathrm{hPa}$ with a decrease in the tropopause height. Randel et al. (2000), using a network of radiosonde stations in the tropical region, reported a cooling trend in tropopause temperature on the order of $-0.5^{\circ} \mathrm{C}$ decade $^{-1}$ during 1979-97 and cautioned that no such trend was found in NCEP reanalysis data. They also observed the warming of the tropopause by $1^{\circ}-2^{\circ} \mathrm{C}$ and the lowering of its altitude by about $200 \mathrm{~m}$ for 2 years following the volcanic eruption of El Chichón in 1982. Recently, Seidel and Randel (2006) studied the trends in the global tropopause and found an increasing trend in tropopause height and a decreasing trend in tropopause temperature; they attributed these changes to stratospheric cooling and tropospheric warming. Wang et al. (2012) conducted a rigorous analysis using four decades of radiosonde data and reported that the tropopause trends have larger uncertainty than existing reports and that tropopause cooling may not be statistically significant. In a very recent study, Randel and Jensen (2013) reported that climate change is expected to influence the tropopause layer through atmospheric circulation, deep convection, air temperature, chemical composition, clouds, and radiation.

Most of the studies used the global average to estimate the tropopause trend, but not on each grid in the global domain. Using different model datasets, Santer et al. (2003) studied the global tropopause trend on each grid and found that the trend in tropopause height is different at different locations; however, this study does not show the global variation of tropopause temperature trends. On a regional scale, considering more than two decades of data of two radiosonde stations in India, Chakrabarty et al. (2000) reported an increasing trend in the tropopause height and decreasing trend in the tropopause temperature; they attributed these changes to the decreasing trend of ozone concentration in the stratosphere. Later, by considering four stations in different parts of India, Chakrabarty et al. (2001) reported that the tropopause trends were not same throughout the period of study and were different at different locations. Bencherif et al. (2006) estimated the long-term trends at different levels in the UTLS region over Durban, South Africa, and found cooling trends at all levels with a maximum cooling rate of $1.09^{\circ} \pm 0.27^{\circ} \mathrm{C} \mathrm{decade}^{-1}$ at $70 \mathrm{hPa}$. They also reported that the magnitude and the sign of trend is seasonally dependent. Over Taipei, using radiosonde data, Thulasiraman et al. (1999) studied the temporal characteristics of the tropopause from 1990 to 1995 and confirmed that the tropopause over Taipei was clearly reflecting the tropical tropopause characteristics observed elsewhere by other investigators. Hsu (2007) found that temperature over Taipei was warming $\left(0.4^{\circ}-\right.$ $0.5^{\circ} \mathrm{C}$ decade $\left.^{-1}\right)$ in the middle to higher troposphere and cooling (about $-2^{\circ} \mathrm{Cdecade}^{-1}$ ) in the lower stratosphere from 1993 to 2002. Das et al. (2012) also reported that the cold-point tropopause over Taiwan varied over different time scales and might relate to outgoing longwave radiation and stratospheric ozone.

In response to the global warming, Taiwan experienced an islandwide warming trend in the surface air temperature in the past 100 years with the warming rate between $1.0^{\circ}$ and $1.4^{\circ} \mathrm{C}$ century ${ }^{-1}$. However, the warming rate for the summer temperature is higher than that for the winter temperature, leading to an increase in the annual temperature range (Hsu and Chen 2002). Expecting the similar seasonal variation in the tropopause trends, we have investigated the trends in the cold-point tropopause characteristics over the Taiwan region using the available long-term radiosonde dataset over Taipei. We have estimated the trends with respect to each month, slightly unlike the earlier studies, which considered the 
continuous time series of annual-mean or monthly-mean data. This is to demonstrate the difference in the trends estimated from the continuous time series and the individual monthly time series data and to verify the seasonality in tropopause trends. This paper is organized as follows. In section 2 , we describe the data that we have used and the methodology that we followed. In section 3 , we examine the annual variation of the tropopause over Taiwan, the trends in tropopause characteristics, and the trends in temperature at different layers of the atmosphere. The possible factors that alter tropopause trends are discussed in section 4. The observed trends are compared with the reanalysis dataset. Section 5 provides the conclusions drawn from this study.

\section{Data and methodology}

The Central Weather Bureau (CWB) of Taiwan launches radiosondes every day at 0000 and 1200 UTC (0800 and 2000 local time, respectively) over Taipei $\left(25^{\circ} 01^{\prime} \mathrm{N}, 121^{\circ} 27^{\prime} \mathrm{E}\right)$, Taiwan, to provide temperature, wind speed, wind direction, and humidity between 0 and $30 \mathrm{~km}$. These radiosondes are of the RS-56 and -76 types before 1984 , the RS-80 and -89 types up to 2010 , and since 2010 they are of the RS-92 Vaisala type. Goodquality data are available from 1981 to 2010 (30 years) at 1200 UTC; however, at 0000 UTC, there was a gap from April 1981 to November 1984 and in April, November, and December 2008. To have continuous data, the present study uses data at 1200 UTC only. However, the work was repeated using the available radiosonde data at 0000 UTC with exactly the same features as observed at 1200 UTC except for small change in magnitudes. The temperature profile from these sondes has been considered to characterize the tropopause. The average vertical resolution of radiosondes around the tropopause region $(15-28 \mathrm{~km})$ is $400 \mathrm{~m}$ with a standard deviation of $100 \mathrm{~m}$. The radiosonde measurement error for the temperature is usually less than $1^{\circ} \mathrm{C}$ (Pratt 1985). Similarly, CWB has also been launching the electrochemical concentration cell (ECC)-based ozonesonde once or twice a month over Taipei since 1992. In addition to the temperature and humidity, the ozonesonde provides the profile of ozone partial pressure, which is a direct indicator of ozone distribution in the atmosphere. In normal meteorological conditions, the ozonesonde reaches an altitude of about $28-35 \mathrm{~km}$. The error in ozone measurement of the ECC ozonesonde is typically less than 5\% in the stratosphere (Beekmann et al. 1994; Logan 1999). The average vertical resolution of the ozonesonde in the lower stratosphere $(18-25 \mathrm{~km})$ is around $100 \mathrm{~m}$ with a standard deviation of $40 \mathrm{~m}$. To eliminate the outliers that arise owing to the random motion of the balloon, both radiosonde and ozonesonde data have been equally gridded to $100-\mathrm{m}$ vertical levels using linear interpolation.

After gridding the daily data, the coldest temperature in the temperature profile has been identified and the corresponding height noted, as shown in the climatological-mean (1981-2010) temperature profile in Fig. 1c. The coldest temperature is identified as the CPT temperature and the corresponding height as the CPT height. In the case of multiple tropopauses, the coldest point after which the temperature increases without inversion is considered as the CPT. We have taken only those radiosonde observations that reached an altitude of $21 \mathrm{~km}$ or more in order to have a complete structure of the tropopause. During the period 1981-2010, the total number of data points available in each month and the number of data points exceeding $21 \mathrm{~km}$ are shown in Fig. 1a. From the figure, it can be seen that on average $80 \%$ of the data crossed $21 \mathrm{~km}$ every month. CPT temperature and height were identified daily, and the daily identified CPT values were then averaged over a month to get monthly means, provided that at least 10 data points are available in that month. Although there are a few cases of double or multiple tropopause structures, because of the relatively small number of cases, monthly-mean heights and temperatures are not affected (Reid and Gage 1996). The time series of monthly anomalies have been obtained by subtracting the climatological-mean values from the monthly-mean time series. We did not apply noise adjustment to tropopause time series because there is no apparent signal noise, such as red noise (Schulz and Mudelsee 2002).

When estimating the long-term trends, the climatological time series should be free from natural and anthropogenic forces (Thompson et al. 2009). Several investigators have used different techniques to suppress the effects of natural variability. Thompson et al. (2009) developed a series of simple, physically based methodologies to isolate the impacts of natural variability in the global-mean surface temperature time series. Similarly, Wu and Huang (2009) developed an ensemble empirical mode decomposition (EEMD) method to decompose the time series into different modes and estimate the linear trends. Although several other methods exist, we have utilized the widely used multivariate linear regression analysis (Randel et al. 2000; Zhou et al. 2001; Chakrabarty et al. 2000, 2001; Bencherif et al. 2006; Austin and Reichler 2008; Sivakumar et al. 2011) to account for the effects of natural variabilities like QBO, ENSO, solar cycles, and volcanic eruptions that will be explained in the later sections. The regression model is of the form 

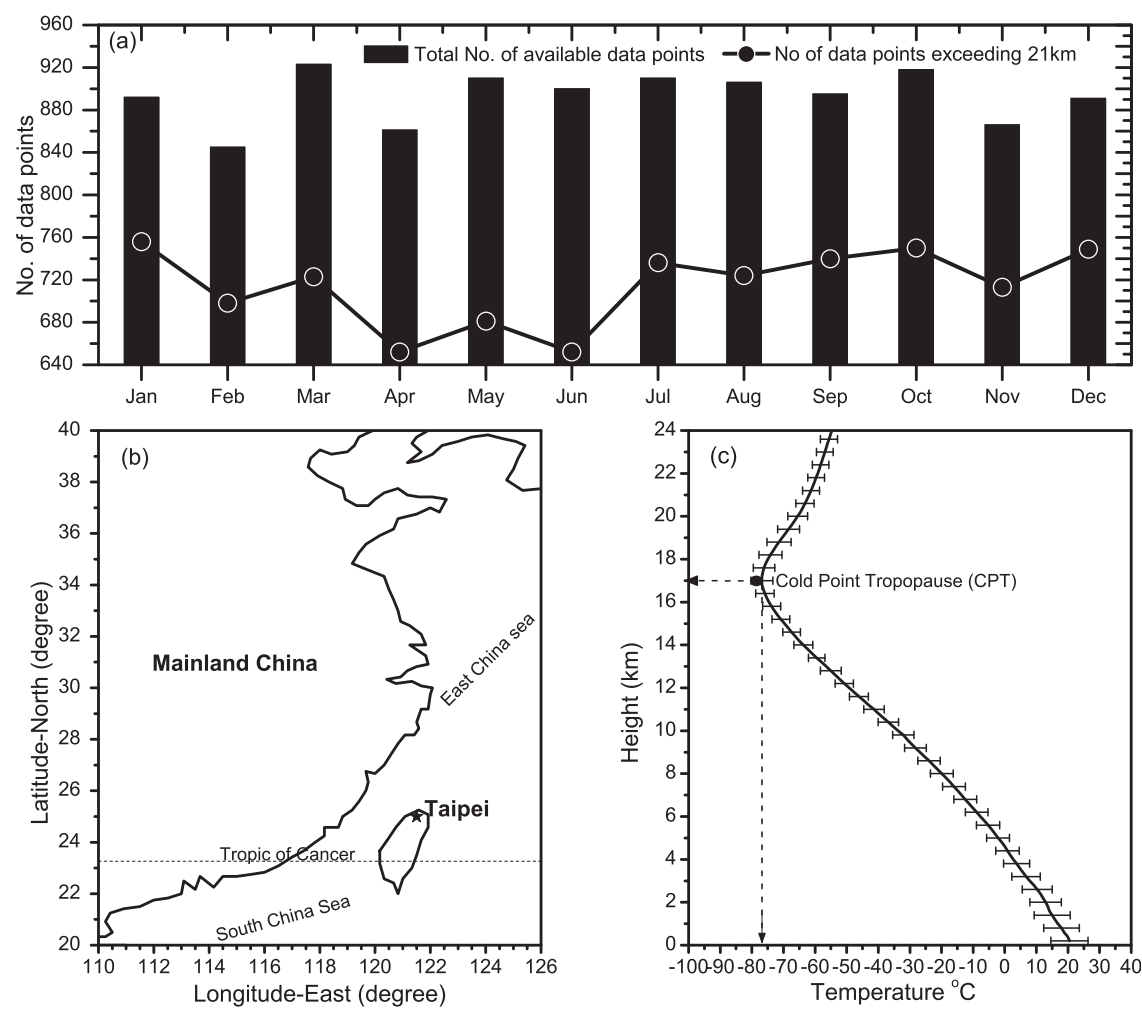

FIG. 1. (a) Monthly available number of data points (bars) and number of data points exceeding $21 \mathrm{~km}$ (line with circles) from radiosondes over Taipei during the period 1981-2010. (b) Geographic location of Taiwan. Location of the observation site Taipei is shown with a star. (c) Climatological-mean (1981-2010) temperature profile along with standard deviation obtained from the radiosondes. The cold-point tropopause and corresponding temperature and height are marked with arrows.

$$
\begin{aligned}
\mathrm{CP}_{t}= & C+C_{1} t+\alpha \mathrm{QBO}_{t}+\beta \mathrm{ENSO}_{t}+\delta \text { Solar }_{t} \\
& +\varepsilon \text { Volcano }_{t}+\text { Residual }
\end{aligned}
$$

where $t=1,2,3, \ldots, 360$ stand for January 1981 to December 2010, $C$ is the constant term, $C_{1}$ is the linear trend, QBO is the $30-\mathrm{hPa}$ zonal monthly-mean wind at the equator, ENSO is the multivariate ENSO index, "solar" is the monthly-mean sunspot number, and "volcano" is the apparent solar transmission over Mauna Loa. The regression coefficients of QBO, ENSO, solar, and volcano factors are $\alpha, \beta, \delta$, and $\varepsilon$, respectively, and "residual" is the residual time series. The resultant time series, which is free from natural variabilities, is then split into individual monthly time series, and the trend for each month is estimated. All the trends are statistically tested with the Student's $t$ test, and the statistically significant trends with greater-than- $95 \%$ confidence levels are only presented unless mentioned. In time series analysis, it is essential to consider the temporal autocorrelation or serial correlation prior to testing for significant trends. The temporal autocorrelation present in the time series has been accounted for using the modified MannKendall test (Hamed and Ramachandra Rao 1998). This method considers the effective number of samples (degrees of freedom) accounting for the temporal autocorrelation if present in the time series, while determining the confidence intervals of the trends. While averaging the seasonal trends (Fig. 6), we also considered only the significant trends, and the insignificant values are omitted. A detailed description and discussion of the natural variability is given in section $3 \mathrm{~b}$.

Further, to explain the observed trends in the tropopause, 31-yr data from the National Centers for Environmental Prediction-Climate Forecast System Reanalysis (NCEP-CFSR) have been considered. NCEP-CFSR was completed for the 31-yr period from 1979 to 2009 in January 2010. This is an improved version of reanalysis data available with a spatial resolution of $0.5^{\circ} \times 0.5^{\circ}$ and with 37 vertical levels starting from 1000 to $1 \mathrm{hPa}$. Although it is not possible to locate exactly the tropopause owing to limited vertical levels, the higher vertical resolution of about $25 \mathrm{hPa}$ near the tropopause helps to identify the near-realistic tropopause, as compared to 

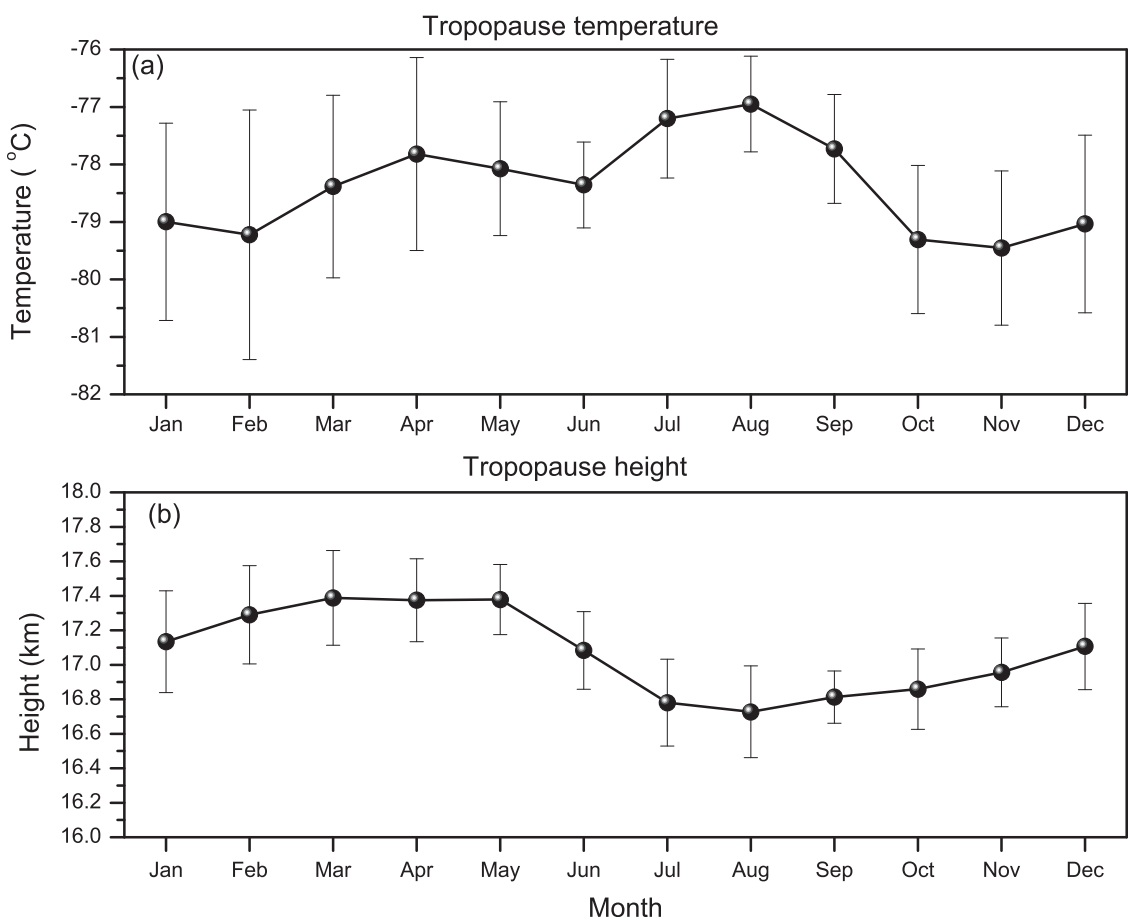

FIG. 2. Climatological-mean annual variation of tropopause (a) temperature and (b) height, along with their standard deviations, observed over Taipei using radiosonde data from 1981 to 2010.

radiosonde observation. The 6-hourly or monthly data can be obtained from http://rda.ucar.edu/pub/cfsr.html. The details of the model improvement and betterment of the data quality can be seen in the work of Saha et al. (2010). To check the effect of convection on tropopause trends, the monthly-mean outgoing longwave radiation (OLR) data that serves as a proxy for convection, obtained from NCEP-National Center for Atmospheric Research (NCAR) for the period from 1981 to 2010 over the study site, are used. OLR data are available with $2.5^{\circ} \times 2.5^{\circ}$ spatial resolution and with temporal coverage of daily, monthly, and long-term means. Complete description of the NCEP-NCAR reanalysis interpolated OLR data can be found in Liebmann and Smith (1996).

\section{Results}

The northern and southern parts of Taiwan are separated by the Tropic of Cancer; the climate is marine tropical owing to the presence of surrounding ocean. The southeastern coast of mainland China is around 100 miles away from Taiwan, separated by the Taiwan Strait. The Taipei observation station is in the northern part of Taiwan, located at the edge of the tropical region as shown in Fig. 1b. This peculiar geographic and climatic condition results in a notable annual variation in the tropospheric temperature that could cause changes in the tropopause characteristics. Although the globalmean annual variation of tropopause is widely discussed in several studies, all the stations within that domain may not exactly exhibit similar variation as that of global mean. Thus, while studying the tropopause characteristics over a station, it is necessary to understand the detailed annual variation over that study region.

\section{a. Annual variation in tropopause}

The long-term-mean annual variation of the tropopause temperature and height over Taipei is shown in Fig. 2. The tropopause has its hottest temperature $-77^{\circ} \mathrm{C}$ during the summer (July-September) and its coldest temperature $-79.5^{\circ} \mathrm{C}$ during October-February, showing significant annual variation of about $2.5^{\circ} \mathrm{C}$. However, the CPT has its peak height of about $17.4 \mathrm{~km}$ during the spring (March-May) and its lowest during the summer (July-September) of about $16.7 \mathrm{~km}$, showing an overall annual variation of less than $1 \mathrm{~km}$. Thus, the tropopause is hotter and lower during the summer over Taipei, but it is not higher when colder. It can be noted here that the tropopause height and temperature are not linearly related in all seasons. This is consistent with the observations made by Chen et al. (2004) and Thulasiraman et al. (1999) at the same location, using the same dataset 

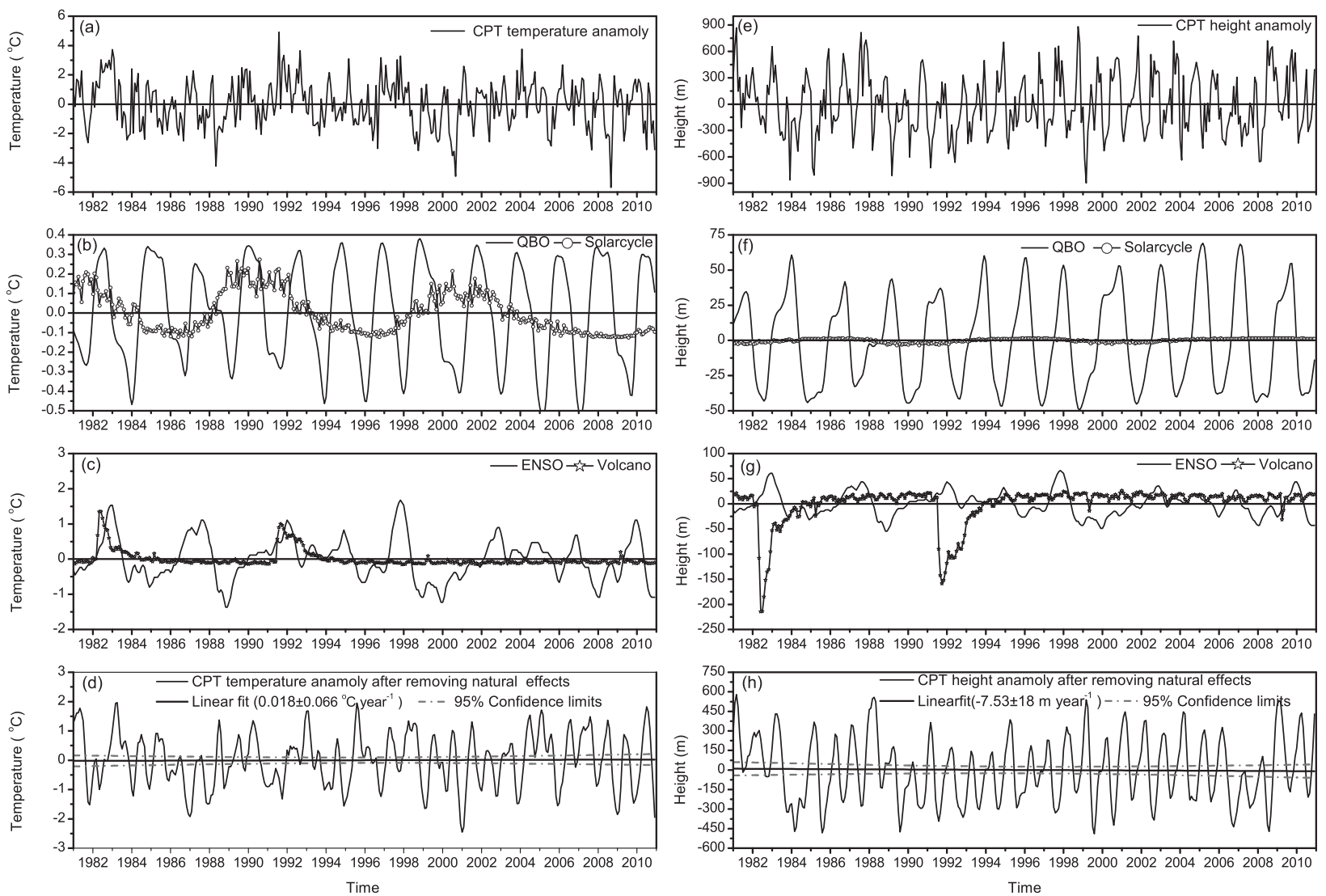

FIG. 3. Time series (1981-2010) of monthly anomalies in (a) tropopause temperature, (b) QBO (solid line) and solar cycle (open circles), and (c) ENSO (solid line) and volcano (open stars) components derived from regression analysis, and (d) time series after removing the natural variability, including volcanic eruption. The solid straight line shows the least squares linear fit to the time series, dashed lines show the $95 \%$ confidence limits, and the trend value is shown in the legend. (e)-(h) As in (a)-(d), respectively, but for tropopause height.

but for different time periods. The observed annual variation is similar to the variation over the tropical western Pacific island of Truk $\left(7.5^{\circ} \mathrm{N}, 151.8^{\circ} \mathrm{E}\right)$, where the tropopause is high and cold during December-April and low and warm during July-September, as observed by Reid and Gage (1996). However, the CPT over Truk Island is about $0.5 \mathrm{~km}$ lower and $3^{\circ}-4^{\circ} \mathrm{C}$ cooler than the CPT over Taipei, and the amplitude of annual variation is smaller over Taipei. Seidel et al. (2001) studied the climatology of the tropopause using radiosonde data from 83 stations in the tropical region and suggested that the longitudes of minimum temperatures differ from the longitudes of maximum height of the tropopause and that these characteristics change seasonally. In all seasons, the tropopause over Taipei is almost at the same height, but it is slightly hotter than the tropical zonal-mean tropopause as observed by Seidel et al. (2001). It is important to note here that the annual-mean CPT height is $17 \pm 0.23 \mathrm{~km}$, which is a typical characteristic of the tropical tropopause (Seidel and Randel 2007). Although the time periods are different, the annual-mean CPT temperature $\left(-78.3^{\circ} \pm 0.8^{\circ} \mathrm{C}\right)$ and height $(17 \pm 0.23 \mathrm{~km})$ are exactly the same as those observed by Das et al. (2012) over the same site.

\section{b. Long-term tropopause trend and effect of natural variabilities}

The long-term trend of the tropopause over the globe has been studied either by considering the time series of monthly-mean or annual-mean tropopause characteristics (Seidel and Randel 2006; de F. Forster and Tourpali 2001; Randel et al. 2000; Zhou et al. 2001; Chakrabarty et al. 2000, 2001; Sivakumar et al. 2011). Following Randel et al. (2000), the tropopause trend over Taipei has been estimated using the time series of monthly-mean tropopause temperature and height anomalies from 1981 to 2010 as shown in Figs. 3a and 3e, respectively. The 3 -month running mean was applied to the time series to suppress the effect of seasonal variability on tropopause.

The variation in the tropopause is also affected by the various natural changes, such as the stratospheric quasi-biennial oscillation (QBO), the tropospheric 
El Niño-Southern Oscillation (ENSO) (Angell and Korshover 1974; Zhou et al. 2001) and episodic volcanic eruptions (Reid and Gage 1985). The large fluctuations observed in the tropopause time series, even after application of the 3-month running mean, may be attributed to the influence of QBO, ENSO, solar activity, and volcanic eruptions (Reid and Gage 1996; Chakrabarty et al. 2000; Randel et al. 2009). In general, fluctuations in tropopause characteristics are caused by variations in lower-stratospheric temperatures, such as thermal wind balance with the QBO in the lower-stratospheric zonal wind (Reid and Gage 1985). Among all natural variabilities, the effect of QBO on tropopause is a wellknown phenomenon. Downward-propagating QBO meridional circulation in the equatorial stratosphere may cause the QBO signature in the CPT (Zhou et al. 2001). Thus, the zonal average of the 30 -hPa zonal wind at the equator (http://www.esrl.noaa.gov/psd/data/correlation/ qbo.data) has been considered as an index to represent the QBO variation (Fig. S1a). In addition, SSTs contribute to changes in the tropopause indirectly by changing the tropospheric and stratospheric circulations (Austin and Reichler 2008). In particular, the SST gradients in the tropical Pacific Ocean modulate the atmospheric circulation that may cause significant variance in tropopause characteristics in the tropical and subtropical regions. Thus, the multivariate ENSO index (MEI) (available from http://www.esrl.noaa.gov/psd/ enso/mei/table.html) is considered to isolate the effect of ENSO (Fig. S1b). More data details can be gathered from the work of Wolter and Timlin (2011). Further, using sunspot number or solar radio flux at a wavelength of $10.7 \mathrm{~cm}$, several authors (Gage and Reid 1981; Randel et al. 2000; Chakrabarty et al. 2000, 2001; Bencherif et al. 2006; Sivakumar et al. 2011) found that there is a statistically significant projection of the 11-yr solar cycle on the tropopause. To account for solar cycle variability, we have considered the monthly-mean sunspot number (Fig. S1c) from the NOAA National Geophysical Data Center (http://www.ngdc.noaa.gov/stp/ solar/ssndata.html).

Solar transmission measured at Mauna Loa Observatory is used as the index of volcanic eruptions in this study. The volcanic ash might stay in the stratosphere for several years (Barnes and Hofmann 1997; Antuña et al. $2002)$ and might have a large impact $\left(\sim 5^{\circ}-6^{\circ} \mathrm{C}\right.$ increase in temperature) on the lower-stratospheric region, increasing the tropopause temperature over Taipei (Fig. S2a) (Thulasiraman et al. 1999). Randel et al. (2000, 2009) also reported that the volcanic eruption of El Chichón (April 1982) warmed the tropical tropopause by about $1^{\circ}-2^{\circ} \mathrm{C}$ and lowered the altitude by about $200 \mathrm{~m}$ for approximately $1-2$ years. To suppress large anomalies in the tropopause owing to volcanic eruption, Randel et al. $(2000,2009)$ omitted the data for 2 years after any large volcanic eruption. Thompson et al. (2009) used the annually averaged global radiative forcing in a regressionbased method to remove the influence of volcanic eruptions from global-mean temperature time series. However, owing to the lack of a well-defined factor to describe the amplitude of a volcanic eruption in the upper troposphere and lower stratosphere, the solar transmission measured at Mauna Loa Observatory is considered to be the index of volcanic eruption. In general, direct broadband solar transmission through a cloud-free atmosphere varies according to changes in atmospheric concentrations of water vapor, aerosols, ozone, and, to a lesser extent, other trace gases. Among these atmospheric constituents, aerosols have the greatest potential influence on fluctuations in the solar transmission record (Dutton et al. 1985; Dutton and Bodhaine 2001). However, downward direct and diffuse radiation measured at Mauna Loa shows that the reduction in direct downward shortwave radiation was almost matched by an enhancement of downward diffuse flux, caused by enhanced forward scattering of incoming solar radiation due to the aerosols following the 1982 El Chichón and 1991 Pinatubo eruptions (Robock 2000; Dutton and Christy 1992). Dutton and Bodhaine (2001) examined the sensitivity of this apparent transmission to aerosols, water vapor, and ozone; they found that most of the variability in apparent transmission is due to aerosols. Thus, we have considered the monthly-mean time series of apparent solar transmission, which is derived from broadband $(0.3-2.8 \mu \mathrm{m})$ direct solar irradiance observations at Mauna Loa Observatory, Hawaii (Ellis and Pueschel 1971), as a proxy for volcanic effect. It is also evident that the apparent solar transmission data measured at Mauna Loa (Fig. S2b) can be used as a proxy for the effect of volcanic eruption.

To suppress the effect of natural variabilities mentioned above, the trends were estimated after removing the corresponding variations from the time series using multivariate linear regression analysis (Rawlings et al. 1998). Before applying the regression analysis, the collinearity between the indices was checked; we found no statistically significant correlation among the indices. The time-lagged correlation between the CPT temperature and the climate indices was also examined, and we found that QBO has a significant correlation with CPT at a time lag of +6 and -10 months exactly, as in the observations made by Zhou et al. (2001). Since the CPT and QBO indices are positively correlated at a time lag of +6 months, we consider the +6 -month-lagged QBO index for further analysis. However, other indices are significantly correlated with CPT temperature at 0 time 
lag. By including these climate indices in the multivariate regression analysis, the effects of natural variabilities were suppressed. The obtained regression coefficients $\alpha$, $\beta, \delta$, and $\varepsilon$ in Eq. (1) are 0.021, 0.70, 0.002, and -9.95 , respectively. After being corrected with a +6 -month time lag, the value of $\alpha$ increased from 0.0048 (no lag) to 0.021 (+6-month lag) for CPT temperature.

The components of QBO and solar cycle variability obtained from the regression are shown in Fig. 3b. The effect of $\mathrm{QBO}$ is a peak anomaly of about $\pm 0.5^{\circ} \mathrm{C}$ throughout the time period, which is in agreement with the latitudinal structure of QBO variation in the tropopause observed by Randel et al. (2000). Their study showed the effect of QBO on the tropopause is greater at the equator and decreases with increasing latitude. Zhou et al. (2001) also observed that the composited tropical CPT temperature is warmer by $0.2^{\circ}-0.3^{\circ} \mathrm{C}$ during westerly shear and $0.2^{\circ}-0.3^{\circ} \mathrm{C}$ colder during easterly shear conditions of QBO. The effect of the solar cycle also has a peak anomaly of about $0.2^{\circ} \mathrm{C}$, and the observed effect of the solar cycle is less compared to the effect of QBO. The fitted time series of CPT temperature for ENSO and volcanic eruption are shown in Fig. 3c. The strongest effects of ENSO, due to the strong ENSO warm phase during 1982/83 and 1997/98, are reflected in the ENSO-fitted temperature anomaly, with a peak strength of about $1.7^{\circ} \mathrm{C}$. This is a little less than the local maximum of tropical tropopause temperature anomalies $\left(2^{\circ}-3^{\circ} \mathrm{C}\right)$ due to the ENSO effect observed by Randel et al. (2000). However, the CPT temperature anomalies due to ENSO observed by Zhou et al. (2001) over the western Pacific region are much less $\left( \pm 0.4^{\circ} \mathrm{C}\right)$ than these two observations. Moreover, a moderate correlation of about $R=0.54$ has been observed between the tropopause temperature and the ENSO index.

Figure $3 \mathrm{c}$ shows that volcanic eruptions heated the tropopause by up to $1.5^{\circ} \mathrm{C}$, with an average value of about $0.6^{\circ} \mathrm{C}$, for 2 years after the volcanic eruptions. Robock (2000) analyzed the global-averaged lowerstratospheric temperature during volcanic periods and found that the lower-stratospheric temperature rose by about $1^{\circ} \mathrm{C}$ for about 2 years after the El Chichón eruption in 1982 and the Pinatubo eruption in 1991, which is close to our result. Compared to all other effects, the tropopause seems to be strongly affected by ENSO and less affected by solar cycle. Although the effect of the solar cycle is less compared to all other effects, it may affect the long-term trend, if not removed from the time series. In particular, the ENSO effect is very strong during February-May and relatively weak during June-September over Taipei. As explained by Hatsushika and Yamazaki (2001), the effect of ENSO and QBO will be greater in the boreal winter and lesser in the boreal summer, and these two effects together can explain $25 \%-50 \%$ of the total variance in the tropopause.

The time series of tropopause temperatures after suppressing the natural effects including volcanic eruptions is shown in Fig. 3d. The fluctuations in the residual time series may be due to the presence of annual components. From the wavelet analysis over the same site reported by Das et al. (2012), it is understood that the annual component dominates CPT height where, as in CPT temperature, the annual component is weak and episodic. It is also noted that the CPT height (CPT temperature) and tropospheric convection (stratospheric ozone) have similar interannual variations over Taipei. The linear trend observed using the method of least squares including the $95 \%$ confidence limits is also shown in Fig. 3d. The temporal autocorrelation present in the continuous time series has been accounted for while estimating the confidence limits using the MannKendall significance test. Even after suppressing the effect of natural variabilities, the CPT temperature shows statistically insignificant heating at a rate of $0.018^{\circ} \pm 0.066^{\circ} \mathrm{Cyr}^{-1}$.

A similar procedure was applied to CPT height and the fitted curves along with the resultant time series, as shown in Figs. 3e-h. In case of CPT height, the significant time lag was also 6 months for QBO, and no time lag was observed for other indices. It can be seen that the effect of QBO has an anomaly of about $\pm 50 \mathrm{~m}$ on CPT height throughout the time period, and solar cycle also has a negligible effect on height compared to QBO. Although the effect of the solar cycle seems to be low, it would partially contribute to the observed trend, and hence the solar component is removed. Similar to CPT temperature, CPT height also increased during the ENSO warm phase and decreased during the cold phase, whereas there is a strong decrease in CPT height due to volcanic eruptions. The residual time series, free from natural variabilities, is shown in Fig. 3h. From the linear fitting to the CPT height time series, a statistically insignificant decreasing trend in height at a rate of $-7.53 \pm 18 \mathrm{~m} \mathrm{yr}^{-1}$ is observed. The observed heating trend in tropopause temperature and the decreasing trend in tropopause height are in contradiction with earlier observations, which reported the decrease in the tropical tropopause temperature and the increase in tropopause height (Chakrabarty et al. 2000, 2001; Randel et al. 2000; Seidel et al. 2001; Sausen and Santer 2003; Randel et al. 2009).

The long-term variation in the natural variability is examined here to determine their possible contributions to the long-term trend of the tropopause. The contributions of the trends in each factor on tropopause trend are 

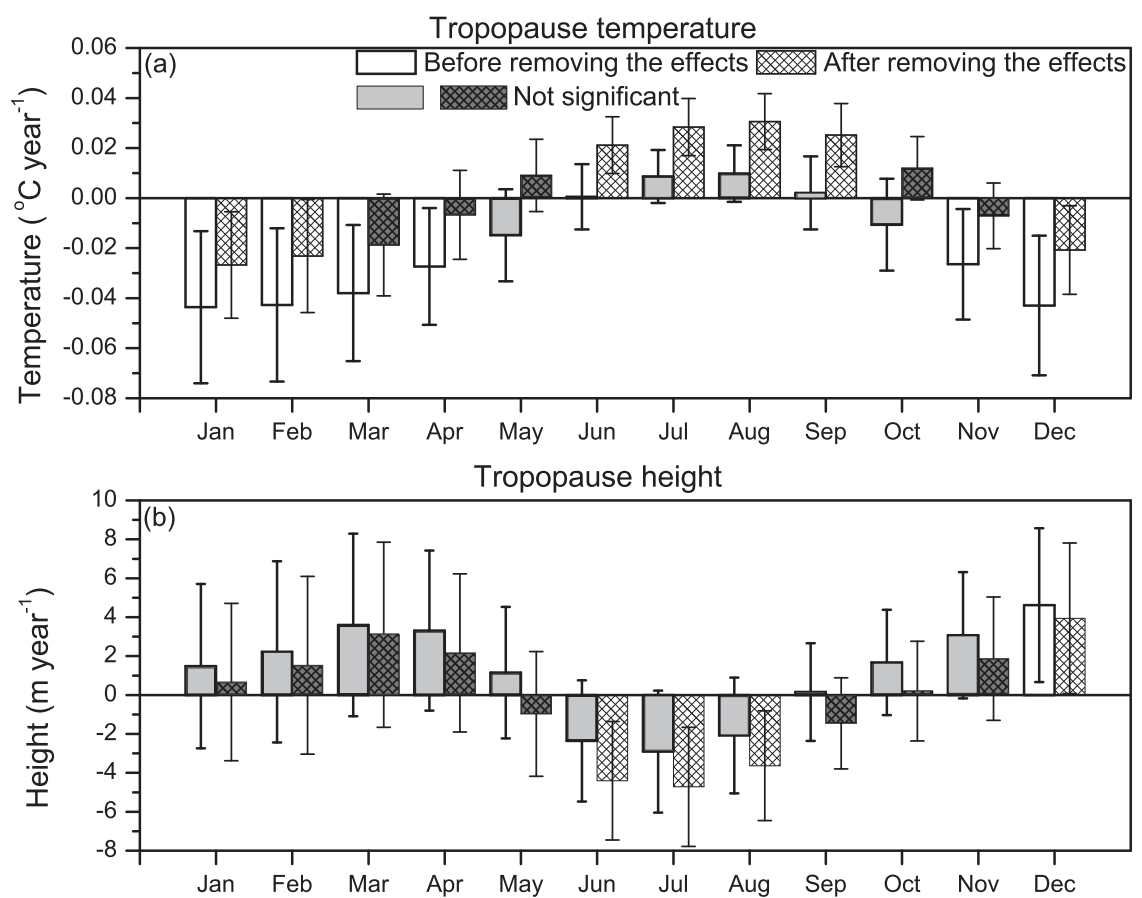

FIG. 4. (a) Monthly trend in tropopause temperature before and after removing the effects using 30 years (1981-2010) of radiosonde data over Taipei. (b) As in (a), but for the tropopause height. Error bars show the two-sigma statistical uncertainties in the regression fits. Open bars represent the statistically significant trends with greater than $95 \%$ confidence and shaded bars represent the statistically insignificant trends with less than $95 \%$ confidence.

found to be $-1.32^{\circ} \times 10^{-3} \pm 1.56^{\circ} \times 10^{-3}{ }^{\circ} \mathrm{Cyr}^{-1}$, $-6.48^{\circ} \times 10^{-3} \pm 3.6^{\circ} \times 10^{-3}{ }^{\circ} \mathrm{C} \mathrm{yr}^{-1}$, and $-4.56^{\circ} \times$ $10^{-3} \pm 0.48^{\circ} \times 10^{-3}{ }^{\circ} \mathrm{C} \mathrm{yr}^{-1}$ in $\mathrm{CPT}$ temperature for QBO, ENSO, and solar cycle, respectively. Among all variabilities, we noticed only sunspot number had a statistically significant decreasing trend. Similarly in CPT height, the contributions are $18 \times 10^{-3} \pm 192 \times$ $10^{-3} \mathrm{~m} \mathrm{yr}^{-1},-252 \times 10^{-3} \pm 144 \times 10^{-3} \mathrm{~m} \mathrm{yr}^{-1}$, and $57.6 \times 10^{-3} \pm 7.2 \times 10^{-3} \mathrm{~m} \mathrm{yr}^{-1}$ for QBO, ENSO, and solar cycle, respectively. After detrending climate indices in the multiregression, the trend of CPT temperature turns from insignificant warming to insignificant cooling with a rate of $-99.6^{\circ} \times 10^{-3} \pm 60^{\circ} \times$ $10^{-3 \circ} \mathrm{Cyr}^{-1}$, and the trend of $\mathrm{CPT}$ height turns from insignificant decreasing to insignificant increasing with a rate of $9.24 \pm 18 \mathrm{~m} \mathrm{yr}^{-1}$ (not shown). This result indicates that the trends in natural variabilities contribute less to the long-term trend of the tropopause. Moreover, using detrended climate indices does not change the monthly variation of CPT trends, as shown in the next section.

\section{c. Monthly trends in tropopause}

The tropopause is dynamically linked to the seasonal variations in the atmospheric temperature, and thus the tropopause is expected to exhibit different trends by season. Keeping this point in view, the tropopause trends have been estimated taking the time series of individual months (Fig. S3); the observed trend in CPT temperature and height for each month is presented. Here, we have checked the individual monthly time series for high-frequency components using a LombScargle periodogram and found that each month's time series is free from significant high-frequency components and also free from temporal autocorrelation. Figure 4 shows the observed monthly trend in CPT temperature and height before and after removing the natural variability from the time series. As expected, it is very interesting to see that the tropopause exhibited clear annual variation in its trends. Except in the months of March, April, May, October, and November, all months show statistically significant trends with a $95 \%$ confidence level. Here the tropopause temperature is seen increasing during June-September with a statistically significant peak heating at a rate of about $0.03^{\circ} \mathrm{C} \mathrm{yr}^{-1}$ in August and statistically significant cooling trends during December-February with a peak cooling rate of about $-0.026^{\circ} \mathrm{C} \mathrm{yr}^{-1}$ in January (Fig. 4a). Moreover, the trends estimated from the time series, which has the natural variabilities suppressed, did not change the 


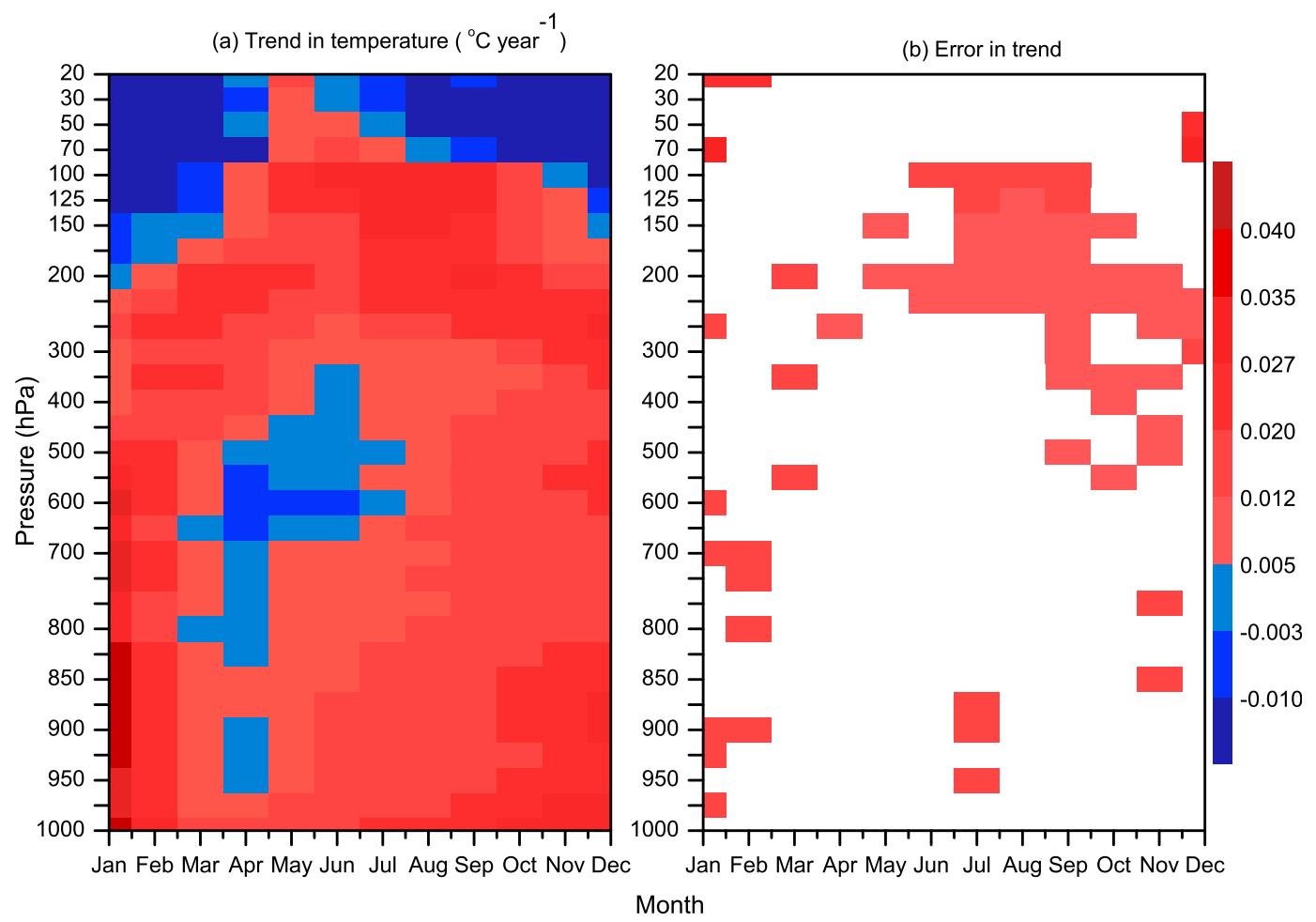

FIG. 5. (a) Trends in the monthly-mean atmospheric temperature at all levels over Taipei using radiosonde data from 1981 to 2010, and (b) corresponding error obtained while estimating the trend at each level using least squares fit. Here only the errors for significant trends with greater than $95 \%$ confidence are shown.

trends obtained from the original time series except for some changes in the magnitude.

The same procedure is applied for the tropopause height. Statistically significant decreasing trends are found during June-August with a peak of about $-4.7 \mathrm{~m} \mathrm{yr}^{-1}$ in July and statistically significant increasing trends in December with a peak of about $3.9 \mathrm{~m} \mathrm{yr}^{-1}$. All other months show statistically insignificant trends. As mentioned above, CPT height and temperature are inversely related but not always. The observed trends in CPT temperature and height have been verified with the EEMD and similar seasonality in tropopause trends found. Here it is clear that the seasonal tropopause trends is shown in Fig. 4 provide detailed information compared to the trends estimated using continuous time series (Figs. 3d and 3h).

\section{d. Temperature trends at different levels}

The tropopause is in the region affected by both the troposphere and the stratosphere. To explain the trends observed above, the monthly trend in different levels of the atmospheric temperature profile is estimated using the radiosonde data from 1981 to 2010 and is shown in Fig. 5a. The uncertainty of corresponding statistically significant trends in Fig. 5a is shown in Fig. 5b. It can be seen that the upper troposphere is getting hotter throughout the year with a statistically significant heating rate at higher levels near the tropopause during summer, at a rate of about $0.03^{\circ} \mathrm{Cyr}^{-1}$, and the lower troposphere is showing cooling/insignificant heating during this period at a rate of $-0.01^{\circ} \mathrm{C} \mathrm{yr}^{-1}$, with a gradual height variation with each month. However, the lower stratosphere is showing an insignificant cooling trend during AugustApril and a slight significant heating trend during summer (May-July) over Taipei.

These observations are consistent with the model simulations made by Austin and Reichler (2008). Using past and future climate simulations, they showed that strong stratospheric cooling counteracted the smaller tropospheric warming and led to tropopause cooling before the year 2000. Increased upwelling caused an increase in tropopause height, whereas after 2000, in comparison, tropospheric warming becomes much more pronounced than stratospheric cooling, and the tropopause therefore warms. Thus, from the observed results, over Taipei, it is evident that enhanced upper-tropospheric warming with decreased lowerstratospheric cooling during summer might have caused the heating trend in the tropopause temperature during summer. Similarly, large lower-stratospheric cooling and 

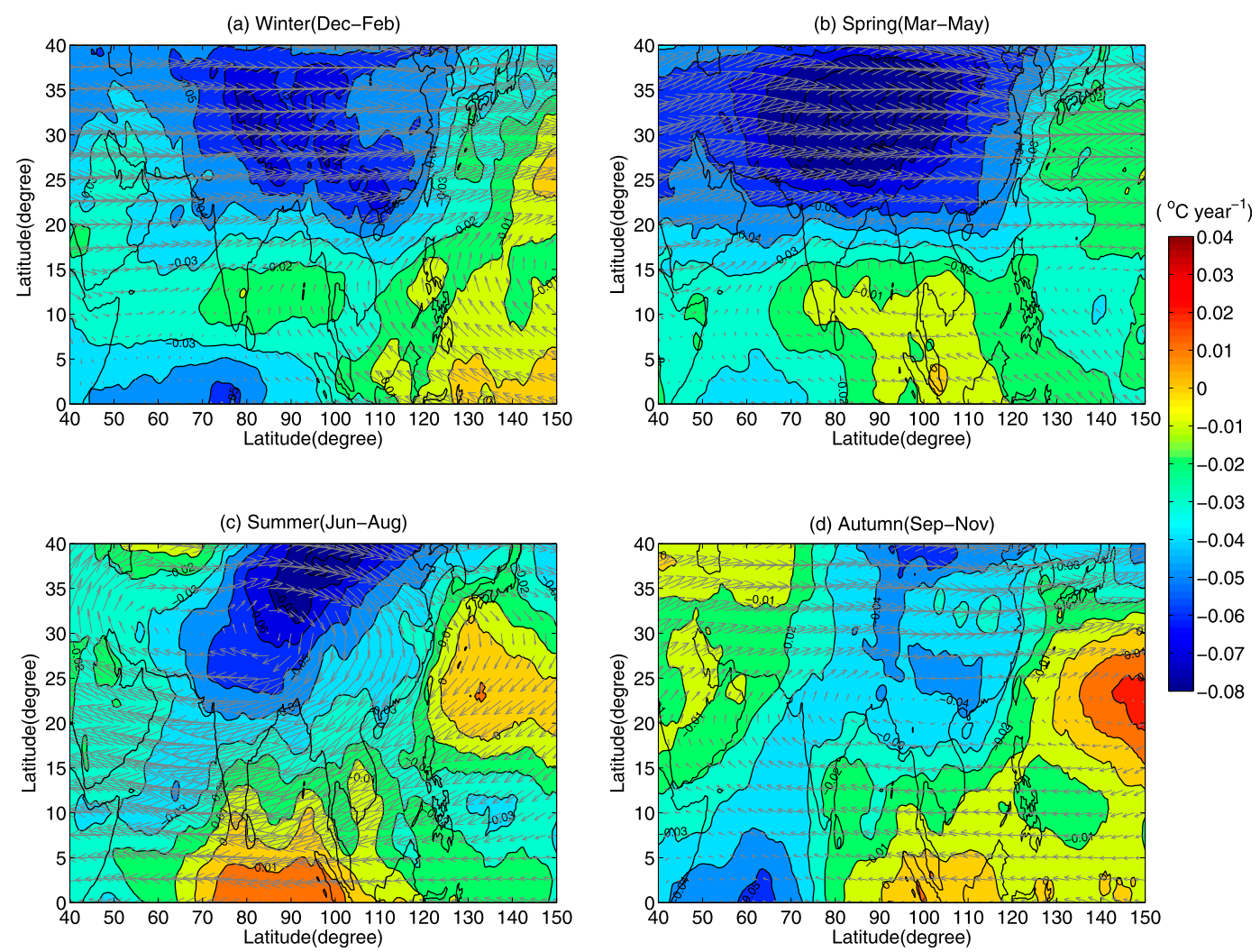

FIG. 6. Seasonal trends in the CPT temperature $\left({ }^{\circ} \mathrm{Cyr}^{-1}\right.$; colors) over the domain $0-40^{\circ} \mathrm{N}, 40-150^{\circ} \mathrm{E}$ using NCEP-CFSR monthly-mean data during 1981-2009. The climatological-mean (1981-2010) vector wind (arrows) at $100 \mathrm{hPa}$ using NCEP reanalysis data is also plotted over the CPT trends.

less upper-tropospheric heating might be responsible for the significant cooling trend in the tropopause during other months.

\section{Discussion}

The observed seasonality in trends may be the result of seasonal variations in the atmospheric temperature, local convection, atmospheric circulation, stratospheric water vapor, and ozone concentrations. Reid and Gage (1981) linked the annual variation in the tropopause characteristics to seasonal variations in solar radiation and its impact on tropical convection. Taiwan lies at the intersection of the Pacific Ocean and the Asian continent; therefore, the observed seasonality in tropopause trends might relate to climate features in Taiwan. The climate system in Taiwan is known as being dominated by Pacific highs in summer and by cold highs from the Asian continent in winter. To discuss the relationship between seasonality in tropopause trends and climate features in Taiwan, the spatial distribution of tropopause trends in each season is examined below.

\section{a. Spatial variation in tropopause temperature trends}

The trend in the CPT temperature at each grid in the domain $0^{\circ}-40^{\circ} \mathrm{N}, 40^{\circ}-150^{\circ} \mathrm{E}$ is estimated using NCEPCFSR data, and the seasonal-mean trends are shown in Fig. 6. The climatological-mean zonal wind (1981-2010) at $100 \mathrm{hPa}$ using NCEP reanalysis data is also plotted in the figure. It is clear from the figures that the temperature trend is not spatially homogeneous and changes with season, perhaps depending upon regional climate change. The subtropical continental region in the Northern Hemisphere shows a large cooling in the tropopause temperature during spring and summer and relatively small cooling during autumn and winter. During the summer season, the tropopause temperature shows slight heating trends over the Taiwan region and large heating in the equatorial south Asian region.

It can be seen here that during the Asian summer monsoon (June-September) there is a large anticyclonic circulation observed within the domain at $100 \mathrm{hPa}$, which is intensified to form the tropical easterly jet. This anticyclone is the dominant circulation feature in the UTLS region during NH summer, which may cause 
the transport of ozone and water vapor into the lower stratosphere. This transport seems largest during $\mathrm{NH}$ summer, which may be attributable to the intense monsoonal circulations (Randel and Jensen 2013). Roja Raman et al. (2009) found that the strength of the Asian monsoon anticyclone has been increasing since the year 2000 . Since the tropopause temperature and stratospheric water vapor are strongly correlated (Randel et al. 2006), the heating rate observed over Taiwan, which is at the edge of the anticyclone, may be attributable to the high moisture transport owing to the increasing strength of the anticyclone during summer season.

Sea surface temperature might indirectly affect the tropopause by changing the tropospheric and stratospheric circulations. Figure 6 shows a statistically significant heating trend in the tropopause over the western Pacific region, with large heating during autumn $\left(\sim 0.02^{\circ} \mathrm{C} \mathrm{yr}^{-1}\right)$ compared to summer $\left(\sim 0.005^{\circ} \mathrm{Cyr}^{-1}\right)$. Using a climate model, Austin and Reichler (2008) studied the relation between the SST and the tropopause temperature and found that these two are anticorrelated at interannual time scales and correlated at multidecadal time scales. Their study also reported that tropopause height and pressure closely follow the upwelling, whereas tropopause temperature is primarily related to SST and ozone. Thus, the heating and cooling rates in the tropopause observed over the western Pacific region might be attributed to SST variations over that region.

\section{b. Ozone trend at the UTLS region}

The increase in ozone concentration might also alter the tropopause trends because of the stratospheric cooling attributed to ozone depletion that might cause increasing tropopause height and cooling in tropopause temperature (Randel et al. 2000; Seidel et al. 2001; Sausen and Santer 2003; Seidel and Randel 2006). Recently, using three different ozone databases, Solomon et al. (2012) found that the decrease of tropical lowerstratospheric ozone in recent decades is uncertain, and this leads to similar uncertainties in the cooling of the tropical lower stratosphere. Using 10 years of ozonesonde observations over Taipei, Hsu (2007) reported that the trends of temperature and ozone are inversely correlated with each other from the middle troposphere up to the lower stratosphere. Chae and Sherwood (2007) suggested that the annual cycle of ozone in the tropical tropopause layer plays an important role in modulating that of temperature. The monthly trends of average ozone mixing ratio in the lower stratosphere obtained from ozonesonde observations over Taipei from 1996 to 2010 are shown in Fig. 7a. Although the data are available from 1992, we have considered the data from 1996 in order to avoid the effects of the Pinatubo volcanic eruption. It is interesting to see that just above the mean tropopause height $(17.5-20.5 \mathrm{~km})$, a statistically significant increasing trend in ozone mixing ratio is observed during the summer season (July-August), with its peak in July at a rate of about $6.4 \times 10^{-3} \mathrm{ppmv} \mathrm{yr}^{-1}$. A statistically significant decreasing trend is observed during December-March with a peak in December at a rate of about $9 \times 10^{-3} \mathrm{ppmv} \mathrm{yr}^{-1}$. The trends in other months are not statistically significant at the $95 \%$ confidence level. Although the rate of increase in ozone concentration is very small during the summer months, this could cause reduced cooling or slight heating in the lower stratosphere as seen in Fig. 5a, which leads to tropopause heating. The observed increase in ozone concentration along with tropopause heating is in agreement with the model simulations reported by Austin and Reichler (2008). Their report suggested that the increase in ozone concentration from the year 2000 would contribute to heating trends in the tropopause temperature until about 2040. The heating trend in the UTLS region is also verified using the radiative transfer model developed by Fu and Liou (1993), and we found that the model output strongly supports our finding. Using Taipei ozonesonde observations in the model, net heating due to a $1 \%$ increase in ozone concentration between 90 and $50 \mathrm{hPa}(\sim 17-21 \mathrm{~km})$ resulted in a marked heating of about $0.3^{\circ} \times 10^{-3}{ }^{\circ} \mathrm{Cday}^{-1}$ $\left(\sim 0.01^{\circ} \mathrm{C} \mathrm{month}^{-1}\right)$ in the UTLS region over Taipei (not shown). The lower-stratospheric ozone depletion during the winter months is likely linked to the cooling trend in tropopause temperatures during winter. To compare the CPT trends with the same period of ozonesonde data, we estimated the CPT temperature trend for the period 1996-2010 and again found a statistically significant heating trend during May-September with a peak heating rate of $0.05^{\circ} \mathrm{Cyr}^{-1}$ in July and a statistically significant cooling trend during December with a peak cooling rate of $-0.055^{\circ} \mathrm{Cyr}^{-1}$ (Fig. 7b). This confirms the seasonality of CPT trends irrespective of the study period.

\section{c. Outgoing longwave radiation and convection strength over Taipei}

Deep convection in general causes strong mixing of the tropospheric air mass and continuously pushes the tropopause upward, deepening the troposphere. Because of deep mixing, the air near the tropopause is dehydrated, and thus the tropopause temperature also decreases. Gettelman et al. (2002) concluded that there is a significant correspondence between the deepest convection and coldest tropopause temperatures on both large and small scales. In the tropics, the relationship is stronger in boreal winter (February) than in boreal summer (August). Since OLR is associated with 

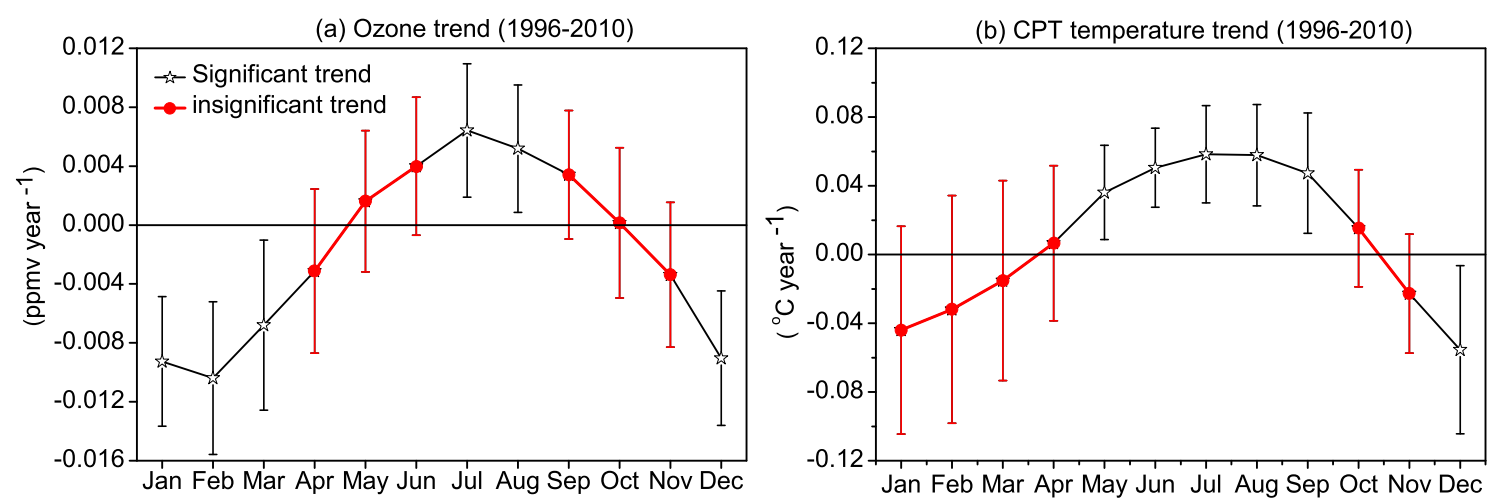

(b) Outgoing Longwave Radiation

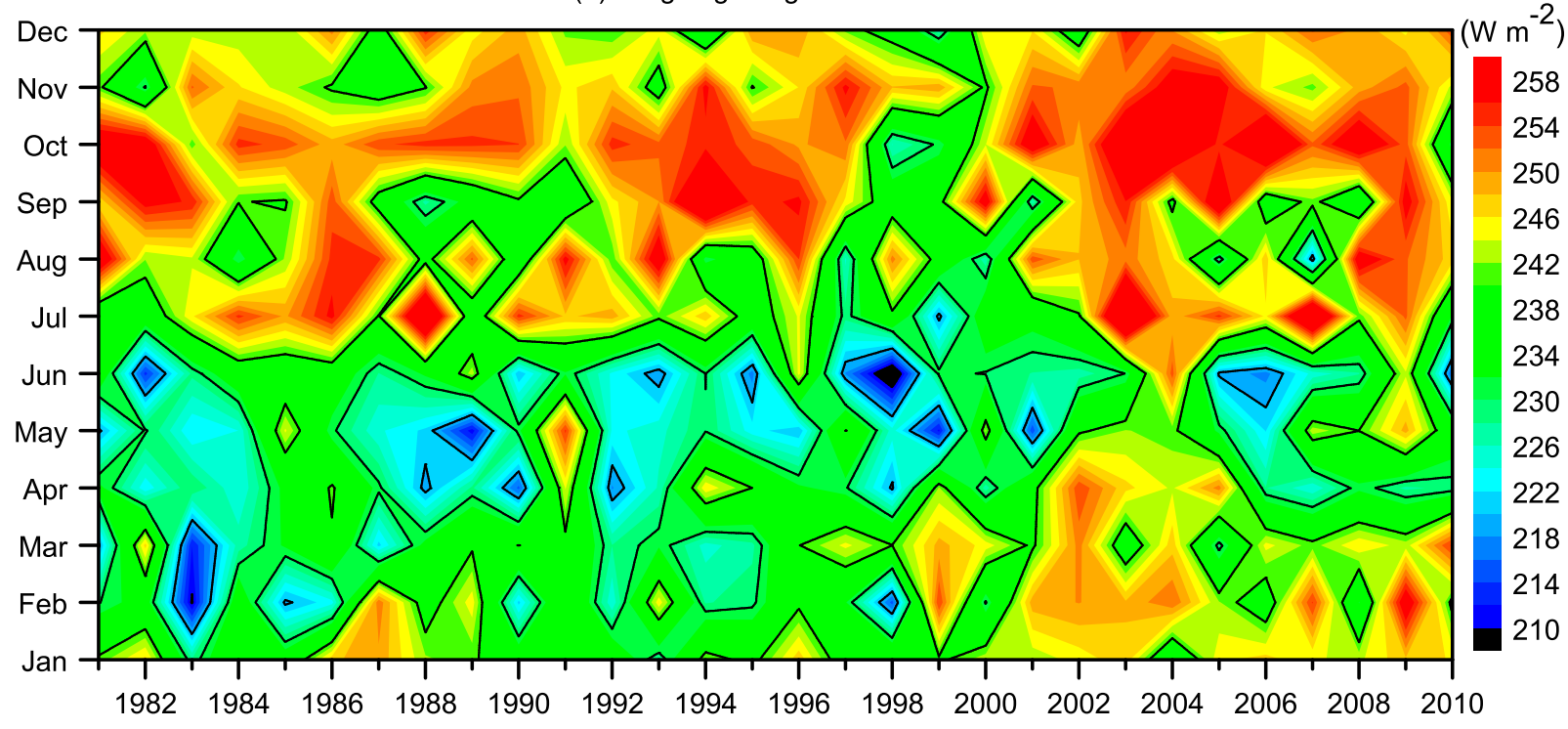

FIG. 7. (a) Monthly trend in mean (17.5-20 km) ozone mixing ratio using ozonesonde observations over Taipei from 1996 to 2010 (error bars show the error obtained while calculating the trend using least squares fit). (b) As in Fig. 4a, but for the period matching ozonesonde observations (1996-2010). Open stars represent the statistically significant trends with greater than 95\% confidence and filled circles represent the statistically insignificant trends with less than $95 \%$ confidence. (c) Time series of monthly-mean OLR from 1981 to 2010 over Taipei grid using NCEP gridded OLR data.

deep convection, we analyzed the time series of monthlymean OLR over Taipei to check the effect of convection on tropopause trends. However, our result, as discussed below, indicates there is no clear evidence to correlate OLR with observed tropopause trends.

The time series of monthly-mean OLR over the Taipei grid from 1981 to 2010 obtained from NCEP reanalysis is shown in Fig. 7c. Since the available grid size is $2.5^{\circ}$ $(\sim 250 \mathrm{~km})$ latitude by longitude, observed convection may not be very localized. Please also note that there is no discontinuity in the satellite instrumentation used for the OLR retrieval during the period of study. In general, an OLR value less than $220 \mathrm{~W} \mathrm{~m}^{-2}$ is considered as the threshold for deep convection (Heddinghaus and Krueger 1981). Here it is interesting to see that strong convection $\left(\mathrm{OLR} \leq 230 \mathrm{~W} \mathrm{~m}^{-2}\right)$ existed from January to
June and relatively less convection (OLR $\geq 240 \mathrm{~W} \mathrm{~m}^{-2}$ ) existed in the other months before the year 1999, whereas the strength of convection during January-April is seen as significantly decreasing (OLR $\geq 240 \mathrm{~W} \mathrm{~m}^{-2}$ ) in the recent decade, with almost no change during summer over Taipei. However, the tropopause cooling with increasing height during January-April does not agree with the theory of effect of convection. Thus, it seems there is no one-to-one correlation with the long-term variation of convection and observed tropopause trends over the observation site.

\section{Concluding remarks}

Assuming the annual variation and spatial heterogeneity in the tropopause trend, an attempt has been made 
to investigate the tropopause trends using long-term data from about three decades. To demonstrate annual variation in trends, the radiosonde data over Taipei, Taiwan, has been considered and a few important results found, as follows:

1) Tropopause characteristics over Taipei exhibited purely tropical characteristics with a mean height always above $16 \mathrm{~km}$, occasionally peaking up to $18 \mathrm{~km}$. The tropopause shows clear annual variation over Taipei with a higher temperature and a lower height during the summer season, but it is not always colder when higher. Moreover, the tropopause was observed as hotter and higher compared to the tropical Pacific island station of Truk and almost at same height, but slightly hotter than, the tropical zonal-mean tropopause.

2) Natural variability like QBO, ENSO, the solar cycle, and volcanic eruptions affect the tropopause structure significantly, with the effect of ENSO being large on tropopause temperature and the effect of volcanoes being large on tropopause height, compared to all other effects.

3) The 30-yr continuous time series of the tropopause over Taipei does not show statistically significant trends even after removing all the natural variability.

4) Monthly tropopause trend analysis shows interesting seasonality in the trend. During summer, the tropopause over Taipei shows a statistically significant warming at a rate of about $0.03^{\circ} \mathrm{C} \mathrm{yr}^{-1}$ (June-September) with a statistically significant decrease in height at a rate of about $-4.7 \mathrm{~m} \mathrm{yr}^{-1}$ (June-August); this is in contrast to earlier studies, which reported the tropopause cooling with an increasing trend in its height. However, during winter months (December-February), the tropopause showed a significant cooling trend at a rate of about $-0.02^{\circ} \mathrm{C} \mathrm{yr}^{-1}$ with a significant trend of increasing height at a rate of about $3.9 \mathrm{~m} \mathrm{yr}^{-1}$ in December. Trends estimated with EEMD also showed similar seasonality in CPT trends.

5) By analyzing the temperature trend at different height levels, we found that tropopause heating during summer months in recent decades was related to the enhanced heating rate in the upper troposphere and the suppressed cooling rate in the lower stratosphere. Similarly, the cooling rate in the other months is due to the high cooling rate in the lower stratosphere and the low heating rate in the upper troposphere.

6) Different tropopause (or temperature) trends in different months might be related to climate features in Taiwan. Pacific highs dominate the climate system in Taiwan in the summer, and cold highs from the Asian continent dominate in winter. NCEP climate forecast reanalysis data show clear spatial heterogeneity in CPT temperature trends, with heating trends in the western Pacific region and cooling trends mostly in the Asian continent that are consistent with our observations.

7) Variations of the tropopause are also found to be related to ozone in the UTLS region. A statistically significant increase in ozone concentration was noticed at $17.5-20.5 \mathrm{~km}$ during the summer at a rate of about $6.4 \times 10^{-3} \mathrm{ppmv} \mathrm{yr}^{-1}$ from 1996 to 2010 . This increasing trend in ozone concentration in the lower stratosphere during summer might cause suppressed cooling rates in that region, leading to tropopause heating. The heating due to an increase in ozone concentration is verified using the radiative transfer model developed by Fu and Liou (1993). Since the ozone trends are estimated using shorter periods and over a single location, these trends needed to be verified with further long-term data over Taiwan and at other locations. The CPT trends estimated for the period from 1996 to 2010 also showed significant CPT heating in summer months and cooling in winter months.

8) The effect of convection on tropopause variation is examined by analyzing OLR around Taiwan. However, no clear relationship was found. During JanuaryApril, OLR has been observed as decreased over Taipei over the recent decade, and there is not much change in the other months. The result suggests there is no one-to-one correlation between the long-term variation of convection and observed trends in tropopause characteristics over Taipei.

Altogether, the global-mean tropopause trends may not exactly represent the regional-scale long-term variations. However, this study concludes that the trends calculated using the individual monthly time series could represent the actual long-term variations, rather than taking the continuous time series that may normalize the annual variations. The other plausible reasons for observed monthly tropopause trends remain to be investigated.

Acknowledgments. The authors are thankful to the Central Weather Bureau (CWB), Taiwan, for providing the radiosonde and ozonesonde data. The authors also want to express their special thanks to the National Oceanic and Atmospheric Administration (NOAA) for providing the CFSR, ENSO index (MEI), sunspot number, and apparent solar transmission data over Mauna Loa. The help from Dr. Chien-Chung Chang in using empirical model decomposition is also greatly appreciated. 


\section{REFERENCES}

Angell, J. K., and J. Korshover, 1974: Quasi-biennial and long-term fluctuations in tropopause pressure and temperature, and the relation to stratospheric water vapor content. Mon. Wea. Rev., 102, 29-34.

Antuña, J. C., A. Robock, G. L. Stenchikov, L. W. Thomason, and J. E. Barnes, 2002: Lidar validation of SAGE II aerosol measurements after the 1991 Mount Pinatubo eruption. J. Geophys. Res., 107 (D14), doi:10.1029/2001JD001441.

Austin, J., and T. J. Reichler, 2008: Long-term evolution of the cold point tropical tropopause: Simulation results and attribution analysis. J. Geophys. Res., 113, D00B10, doi:10.1029/ 2007JD009768.

Barnes, J. E., and D. J. Hofmann, 1997: Lidar measurements of stratospheric aerosol over Mauna Loa Observatory. Geophys. Res. Lett., 24 (15), 1923-1926.

Beekmann, M., G. Ancellet, G. Mégie, H. G. J. Smit, and D. Kley, 1994: Intercomparison campaign of vertical ozone profiles including electrochemical sondes of ECC and Brewer-Mast type and a ground based UV-differential absorption lidar. J. Atmos. Chem., 19, 259-288.

Bencherif, H., R. D. Diab, T. Portafaix, B. Morel, P. Keckhut, and A. Moorgawa, 2006: Temperature climatology and trend estimates in the UTLS region as observed over a southern subtropical site, Durban, South Africa. Atmos. Chem. Phys., 6, 5121-5128.

Chae, J. H., and S. C. Sherwood, 2007: Annual temperature cycle of the tropical tropopause: A simple model study. J. Geophys. Res., 112, D19111, doi:10.1029/2006JD007956.

Chakrabarty, D. K., N. C. Shah, K. V. Pandya, and S. K. Peshin, 2000: Long-term trend of tropopause over New Delhi and Thiruvananthapuram. Geophys. Res. Lett., 27, 2181-2184.

_ , K. V. Pandya, and N. C. Shah, 2001: Long-term trend of tropopause. Adv. Space Res., 28, 981-986.

Chen, W. N., C. C. Tsao, and J. B. Nee, 2004: Rayleigh lidar temperature measurements in the upper troposphere and lower stratosphere. J. Atmos. Sol. Terr. Phys., 66, 39-49.

Das, S. K., S. S. Das, C. W. Chiang, K. K. Kumar, and J. B. Nee, 2012: Variability in tropopause height and its temperature on different time scales: An observational study over Banqiao, Taiwan. J. Atmos. Sol. Terr. Phys., 81-82, 1-8.

de F. Forster, P. M., and K. Tourpali, 2001: Effect of tropopause height changes on the calculation of ozone trends and their radiative forcing. J. Geophys. Res., 106 (D11), 12241-12251.

Dutton, E. G., and J. R. Christy, 1992: Solar radiative forcing at selected locations and evidence for global lower tropospheric cooling following the eruption of El Chichón and Pinatubo Geophys. Res. Lett., 19, 2313-2316.

_ and B. A. Bodhaine, 2001: Solar irradiance anomalies caused by clear-sky transmission variations above Mauna Loa: 195899. J. Climate, 14, 3255-3262.

_ J. J. DeLuisi, and P. Arne, 1985: Interpretation of Mauna Loa atmospheric transmission relative to aerosols, using photometric precipitable water amounts. J. Atmos. Chem., 3, 53-68.

Ellis, H. T., and R. F. Pueschel, 1971: Solar radiation: Absence of air pollution trends at Mauna Loa. Science, 172, 845-846.

$\mathrm{Fu}$, Q., and K. N. Liou, 1993: Parameterization of the radiative properties of cirrus clouds. J. Atmos. Sci., 50, 2008-2025.

Fueglistaler, S., A. E. Dessler, T. J. Dunkerton, I. Fu, Q. Folkins, and P. W. Mote, 2009: Tropical tropopause layer. Rev. Geophys., 47, RG1004, doi:10.1029/2008RG000267.
Gage, K. S., and G. C. Reid, 1981: Solar variability and the secular variation in the tropical tropopause. Geophys. Res. Lett., 8, 187-190.

Gettelman, A., M. L. Salby, and F. Sassi, 2002: Distribution and influence of convection in the tropical tropopause region. J. Geophys. Res., 107, 4080, doi:10.1029/2001JD001048.

—_, and Coauthors, 2010: Multimodel assessment of the upper troposphere and lower stratosphere: Tropics and global trends. J. Geophys. Res., 115, D00M08, doi:10.1029/ 2009JD013638.

Hamed, K. H., and A. Ramachandra Rao, 1998: A modified Mann-Kendall trend test for auto correlated data. J. Hydrol., 204 (1-4), 182-196.

Hatsushika, H., and K. Yamazaki, 2001: Interannual variations of temperature and vertical motion at the tropical tropopause associated with ENSO. Geophys. Res. Lett., 28, 2891-2894.

Heddinghaus, T. R., and A. F. Krueger, 1981: Annual and interannual variations in outgoing longwave radiation over the tropics. Mon. Wea. Rev., 109, 1208-1218.

Hofmann, D. J., J. M. Rosen, and T. J. Pepin, 1974: Influence of the tropopause height on the global stratospheric aerosol burden and implications for the recent increase in ozone. J. Appl. Meteor., 13, 734-737.

Holton, J. R., P. H. Haynes, M. E. McIntyre, A. R. Douglass, R. B. Rood, and L. Pfister, 1995: Stratosphere-troposphere exchange. Rev. Geophys., 33, 403-439, doi:10.1029/95RG02097.

Hsu, H. H., and C. T. Chen, 2002: Observed and projected climate change in Taiwan. Meteor. Atmos. Phys., 79, 87-104.

Hsu, K. J., 2007: Relationships between ten-year trends of tropospheric ozone and temperature over Taiwan. Sci. Total Environ., 374, 135-142.

Lewis, H. W., 2009: A robust method for tropopause altitude identification using GPS radio occultation data. Geophys. Res. Lett., 36, L12808, doi:10.1029/2009GL039231.

Liebmann, B., and C. A. Smith, 1996: Description of a complete (interpolated) outgoing longwave radiation dataset. Bull. Amer. Meteor. Soc., 77, 1275-1277.

Logan, J. A., 1999: An analysis of ozonesonde data for the lower stratosphere: Recommendations for testing models. J. Geophys. Res., 104, 16151-16170.

Nishimoto, E., and M. Shiotani, 2012: Seasonal and interannual variability in the temperature structure around the tropical tropopause and its relationship with convective activities. J. Geophys. Res., 117, D02104, doi:10.1029/2011JD016936.

Pratt, R. W., 1985: Review of radiosonde humidity and temperature errors. J. Atmos. Oceanic Technol., 2, 404-407.

Randel, W. J., and E. J. Jensen, 2013: Physical processes in the tropical tropopause layer and their roles in a changing climate. Nat. Geosci., 6, 169-176.

, F. Wu, and D. J. Gaffen, 2000: Interannual variability of the tropical tropopause derived from radiosonde data and NCEP reanalyses. J. Geophys. Res., 105 (D12), 15 509-51 523.

,,- H. Vömel, G. E. Nedoluha, and P. Forster, 2006: Decreases in stratospheric water vapor after 2001: Links to changes in the tropical tropopause and the Brewer-Dobson circulation. J. Geophys. Res., 111, D12312, doi:10.1029/ 2005JD006744.

, R. R. Garcia, N. Calvo, and D. Marsh, 2009: ENSO influence on zonal mean temperature and ozone in the tropical lower stratosphere. Geophys. Res. Lett., 36, L15822, doi:10.1029/ 2009GL039343.

Rawlings, J. O., S. G. Pantula, and D. A. Dickey, 1998: Applied Regression Analysis: A Research Tool. Springer, 658 pp. 
Reid, G. C., and K. S. Gage, 1981: On the annual variation in height of the tropical tropopause. J. Atmos. Sci., 38, 1928-1938.

- and 1985: Interannual variations in the height of the tropical tropopause. J. Geophys. Res., 90 (D3), 5629-5635, doi:10.1029/JD090iD03p05629.

_- and —_, 1996: The tropical tropopause over the western Pacific: Wave driving, convection, and the annual cycle. J. Geophys. Res., 101 (D16), 21 233-21241, doi:10.1029/ 96JD01622.

Robock, A., 2000: Volcanic eruptions and climate. Rev. Geophys., 38, 191-219, doi:10.1029/1998RG000054.

Roja Raman, M., V. V. M. Jagannadha Rao, M. Venkat Ratnam, M. Rajeevan, S. V. B. Rao, D. Narayana Rao, and N. Prabhakara Rao, 2009: Characteristics of the tropical easterly jet: Long-term trends and their features during active and break monsoon phases. J. Geophys. Res., 114, D19105, doi:10.1029/ 2009JD012065.

Saha, S., and Coauthors, 2010: The NCEP Climate Forecast System Reanalysis. Bull. Amer. Meteor. Soc., 91, 1015-1057.

Santer, B. D., and Coauthors, 2003: Behavior of tropopause height and atmospheric temperature in models, reanalysis, and observations: Decadal changes. J. Geophys. Res., 108, 4002, doi:10.1029/2002JD002258.

Sausen, R., and B. D. Santer, 2003: Use of changes in tropopause height to detect human influences on climate. Meteor. Z., 12, 131-136.

Schulz, M., and M. Mudelsee, 2002: REDFIT: Estimating red-noise spectra directly from unevenly spaced paleoclimatic time series. Comput. Geosci., 28, 421-426.

Seidel, D. J., and W. J. Randel, 2006: Variability and trends in the global tropopause estimated from radiosonde data. J. Geophys. Res., 111, D21101, doi:10.1029/2006JD007363.

, and - 2007: Recent widening of the tropical belt: Evidence from tropopause observations. J. Geophys. Res., 112, D20113, doi:10.1029/2007JD008861.
R. J. Ross, J. K. Angell, and G. C. Reid, 2001: Climatological characteristics of the tropical tropopause as revealed by radiosondes. J. Geophys. Res., 106 (D8), 7857-7878.

Selkirk, H. B., 1993: Tropopause cold trap in the Australian monsoon during STEP/AMEX 1987. J. Geophys. Res., 98 (D5), 8591-8610.

Sivakumar, V., H. Bencherif, N. Bègue, and A. M. Thompson, 2011: Tropopause characteristics and variability from $11 \mathrm{yr}$ of SHADOZ observations in the southern tropics and subtropics. J. Appl. Meteor. Climatol., 50, 1403-1416.

Solomon, S., P. J. Young, and B. Hassler, 2012: Uncertainties in the evolution of stratospheric ozone and implications for recent temperature changes in the tropical lower stratosphere. Geophys. Res. Lett., 39, L17706, doi:10.1029/2012GL052723.

Son, S. W., and Coauthors, 2009: The impact of stratospheric ozone recovery on tropopause height trends. J. Climate, 22, 429-445.

Thompson, D. W. J., J. M. Wallace, P. D. Jones, and J. J. Kennedy, 2009: Identifying signatures of natural climate variability in time series of global-mean surface temperature: Methodology and insights. J. Climate, 22, 6120-6141.

Thulasiraman, S., J. B. Nee, W. N. Chen, and J. H. Chen, 1999: Temporal characteristics of tropopause and lower stratosphere over Taiwan during 1990-1995. J. Atmos. Sol. Terr. Phys., 61, 1299-1306.

Wang, J. S., D. J. Seidel, and M. Free, 2012: How well do we know recent climate trends at the tropical tropopause? J. Geophys. Res., 117, D09118, doi:10.1029/2012JD017444.

Wolter, K., and M. S. Timlin, 2011: El Niño/Southern Oscillation behaviour since 1871 as diagnosed in an extended multivariate ENSO index (MEI.ext). Int. J. Climatol., 31, 1074-1087.

Wu, Z., and N. E. Huang, 2009: Ensemble empirical mode decomposition: A noise-assisted data analysis method. Adv. Adapt. Data Anal., 1, 1-41.

Zhou, X. L., M. A. Geller, and M. H. Zhang, 2001: Tropical cold point tropopause characteristics derived from ECMWF reanalyses and soundings. J. Climate, 14, 1823-1838. 